\title{
Why do Low-Income, High-Achieving Students not Apply to Top Universities?
}

\author{
Tanisha Srivatsa ${ }^{1}$ and Henry Weeks ${ }^{\#}$ \\ ${ }^{1}$ Mission San Jose High School, Fremont, CA, USA \\ \#Advisor
}

ABSTRACT

In this study, the behavior of low-income, high-achieving students when applying to prestigious universities is analyzed. It was postulated that this behavior is due to a lack of information provided to these students and the effect of several behavioral heuristics that influence these students' application decisions - namely, availability, simulation, and the status quo bias. This paper focuses on the behavior of low-income, high-achieving students who do not apply to prestigious students and therefore behave in a manner typical to their income level rather than their ability. These students, who are less likely to attend magnet schools or live in major metropolitan areas, are often left out of initiatives and college resources available to high-income students. To address this disparity, two solutions are proposed to encourage income-typical students to apply to prestigious universities: the continuation of test-optional policies and virtual college tours.

\section{Introduction}

This study illustrates the phenomenon of why high-achieving disadvantaged students do not apply to prestigious universities, as opposed to high-achieving, high-income students, who are far more likely to apply to prestigious universities despite possessing similar test scores and grade point averages as their lower-income counterparts. The American college admissions process is focused on, with particular emphasis on the 2020-21 and 2021-22 admissions cycles to analyze the effect of the COVID-19 pandemic on college applications. For the purpose of this study, "high-achieving" students are defined as those scoring at or above the 90th percentile on the ACT or the SAT I (math and verbal sections), and have a grade-point average of A- or above. "Prestigious universities" are categorized as those in the "Very Competitive Plus" through "Most Competitive" sections in Barron's Profile of American Colleges (2008), which number 236 in total. ${ }^{1}$

This study will also examine the reasons why these low-income, high-achieving students do not apply to prestigious universities, despite these universities often offering financial aid and merit scholarships that reduce the cost of tuition to lower than the cost of attending a state flagship school. In 2021, the average cost of attending an Ivy League university is $\$ 57,572$, with Columbia University in the City of New York at the highest tuition cost of \$61,671. Although this cost is dramatically higher than the average cost of attending a state flagship school. For example, an average of 22 California State University campuses found that the average cost of tuition for one year at a California state institution was $\$ 7478$, more than seven times less than the average cost of attending an Ivy League university. ${ }^{2}$

\footnotetext{
${ }^{1}$ Hoxby, Caroline, and Christopher Avery. "The Missing 'One-Offs': The Hidden Supply of High-Achieving, Low Income Students." 2012, doi:10.3386/w18586.

${ }^{2}$ Data sampled from 2021-22 Estimated Undergraduate Cost of Attendance for California State University schools. https://www2.calstate.edu/attend/paying-for-college/Documents/21-22-coa.pdf
} 
However, these data points do not consider the generous financial aid packages that prestigious universities are more inclined to grant their students. At all eight Ivy League universities, families earning less than $\$ 60,000$ a year are not required to contribute toward tuition, and at Dartmouth College, this grace threshold is extended to families earning less than $\$ 100,000$ annually. ${ }^{3}$ For families earning between $\$ 60,000$ and $\$ 100,000$, tuition costs are adjusted to fall within a 0 to $10 \%$ range of the family's income; in other words, the maximum cost of tuition for these families would be $\$ 10,000 .{ }^{4}$ In addition, during the COVID-19 pandemic, Princeton University imposed a $10 \%$ tuition cut to compensate for the school's heavy reliance on distance learning in the 2020-2021 academic year. ${ }^{5}$ Therefore, we see that even the costs of attending prestigious Ivy League universities can be dramatically reduced with the consideration of financial aid packages. For so-called “public Ivies," like the University of Michigan and the University of California system, a family's financial contribution can be reduced even further with the use of in-state tuition cuts. This phenomenon, however, contradicts the general pattern seen with low-income, high-achieving students, which is that they do not apply to these prestigious universities.

It is also significant to note the distinction between low-income, high-achieving students who do not apply to prestigious universities (defined as "income-typical" students) and those who do apply to prestigious universities (defined as "achievement-typical" students). Income-typical students behave in a way that corresponds with their family's income and socioeconomic status in restricting themselves to lower-cost universities. Achievement-typical students, on the other hand, apply to universities that match their academic strengths based on factors such as average SAT I scores and mean GPA. However, the number of achievement-typical students is far lesser than the number of income-typical students, and the few achievement-typical students that do exist are often concentrated in a few "bigname" public and private feeder high schools where they are surrounded by similarly motivated high-achievement students. In New York City, for example, all 8th and 9th grade students are administered the Specialized High School Admissions Test, a comprehensive examination that determines students' acceptance to eight of the city's nine Specialized High Schools. These Specialized High Schools, which include "big-name" high schools such as the Bronx High School for Science and Stuyvesant High School, are all considered feeder schools to Ivy League Universities. This phenomenon is also prevalent in private feeder high schools - Horace Mann, a private New York City K-12 school, sent 93 students to the University of Chicago (a "top 10 university"). ${ }^{6}$

K-12 education in the United States is largely complicated by the disparities in the education offered to privileged versus underprivileged students; students from the latter category often suffer from a lack of resources, including a higher student-to-teacher ratio, less qualified teaching staff, and fewer course offerings. Achievementtypical students are able to bridge this gap by attending competitive public or private feeder high schools, where they have access to greater resources regarding the college admissions process and academic offerings. However, the majority of underprivileged students at top-tier universities come from these feeder high schools, leaving out the majority

\footnotetext{
${ }^{3}$ Borden, Taylor. "How Ivy League Financial Aid Packages Stack up, Even amid the Coronavirus Pandemic." Business Insider, Business Insider, 4 Sept. 2020, www.businessinsider.com/how-ivy-league-financial-aid-packages-stackup-coronavirus-tuition-2020-7.

${ }^{4}$ Sample calculations from Harvard University's Net Price Calculator for cost of tuition. https://college.harvard.edu/financial-aid/net-price-calculator

5 "Princeton Announces Plan for Fall 2020, Guidelines for Undergraduates Returning to Campus." Princeton University, The Trustees of Princeton University, 6 July 2020, www.princeton.edu/news/2020/07/06/princeton-announcesplan-fall-2020-guidelines-undergraduates-returning-campus.
}

${ }^{6}$ Martinez, Berenice, et al. Another 4 Years of High School: The Stuyvesant and Horace Mann to UChicago Pipeline. 6 Dec. 2020, cpb-us-w2.wpmucdn.com/voices.uchicago.edu/dist/8/2937/files/2020/11/MartinezReyesSong-Final-Paper.docx. 
of low-income, high-achieving students who attend "regular" public high schools. This difference is compounded by the fact that underprivileged students at regular public high schools are disproportionately affected by other factors such as socioeconomic status, racial identity, and geography. ${ }^{7}$ Clearly, a student's high school environment can shape the available post-secondary education options they choose to pursue. Therefore, income-typical students who do not attend these feeder high schools are left behind by the college admissions process and lose out on valuable opportunities to counter their lower socioeconomic status with high-quality education. This phenomenon of "undermatching," or low-income, high-achieving students not applying to universities that match their student profile, is based on a combination of heuristics that we will examine in more detail later.

In this paper, a comprehensive determination of the process by which we categorized low-income, highachieving students, a summary of current policies targeted toward this population of students, a description of the behavioral heuristics that shape these students' college decisions, and finally, a proposal of possible interventions that could make the college admissions process more equitable for these students are presented.

\section{Defining Low-Income, High-Achieving Students}

Here, the population of low-income, high-achieving students based on socioeconomic status and geography is defined. For the purpose of this study, race is excluded as a factor defining underprivileged students, although it is to be acknowledged that race plays a significant role in an applicant's life and can compound existing disadvantages of income and geography due to pre-existing biases and discrimination against minority races. As per Avery and Hoxby (2012) and the description in the introduction above, high-achieving students are defined as those scoring in the top 10 percentile on the ACT and the SAT I (verbal and math portions), two commonly-used standardized tests integral to the college admissions process, and who have an average grade-point average of an A- or above. This standardized testing data was drawn from the ACT and College Board's released testing data from students of the high school graduating class of 2008, which included more than 933,000 and 2,400,000 students for each test respectively. As based on Avery and Hoxby's determination of low-income students based on the United States Census, IRS data, and a student's high school profile - the study chose to leave out the self-reported income question on the SAT I and ACT because of potential student error and the fact that less than $40 \%$ of students answer this question - the researchers defined "low-income" students as those below the 25 th quartile of the 2008 distribution of households with a child in the graduating class of 2008; that is, families with a combined income below $\$ 41,472^{8}$. On the other hand, "high-income" students were defined as those in the top quartile of the same data set, with family incomes of above $\$ 120,776 .^{9}$

\footnotetext{
${ }^{7}$ Engberg, Mark E., and Gregory C. Wolniak. "Examining the Effects of High School Contexts on Postsecondary Enrollment." Research in Higher Education, vol. 51, no. 2, 2010, pp. 132-153. JSTOR, www.jstor.org/stable/40542368. Accessed 15 May 2021.

${ }^{8}$ Freeberg, N. 1988. "Accuracy of Student Reported Information." College Board Report Number 88-5. http://professionals.collegeboard.com/profdownload/pdf/RR\%2088-5.PDF

${ }^{9}$ Bureau, US Census. "2008 Comparison Guidance." The United States Census Bureau, 9 Sept. 2020, www.census.gov/programs-surveys/acs/guidance/comparing-acs-data/2008.html.
} 


\section{Figure 1}

\section{Distribution of Family Income Among Fam ilies with a Child in the 12 th Grade, 2008}

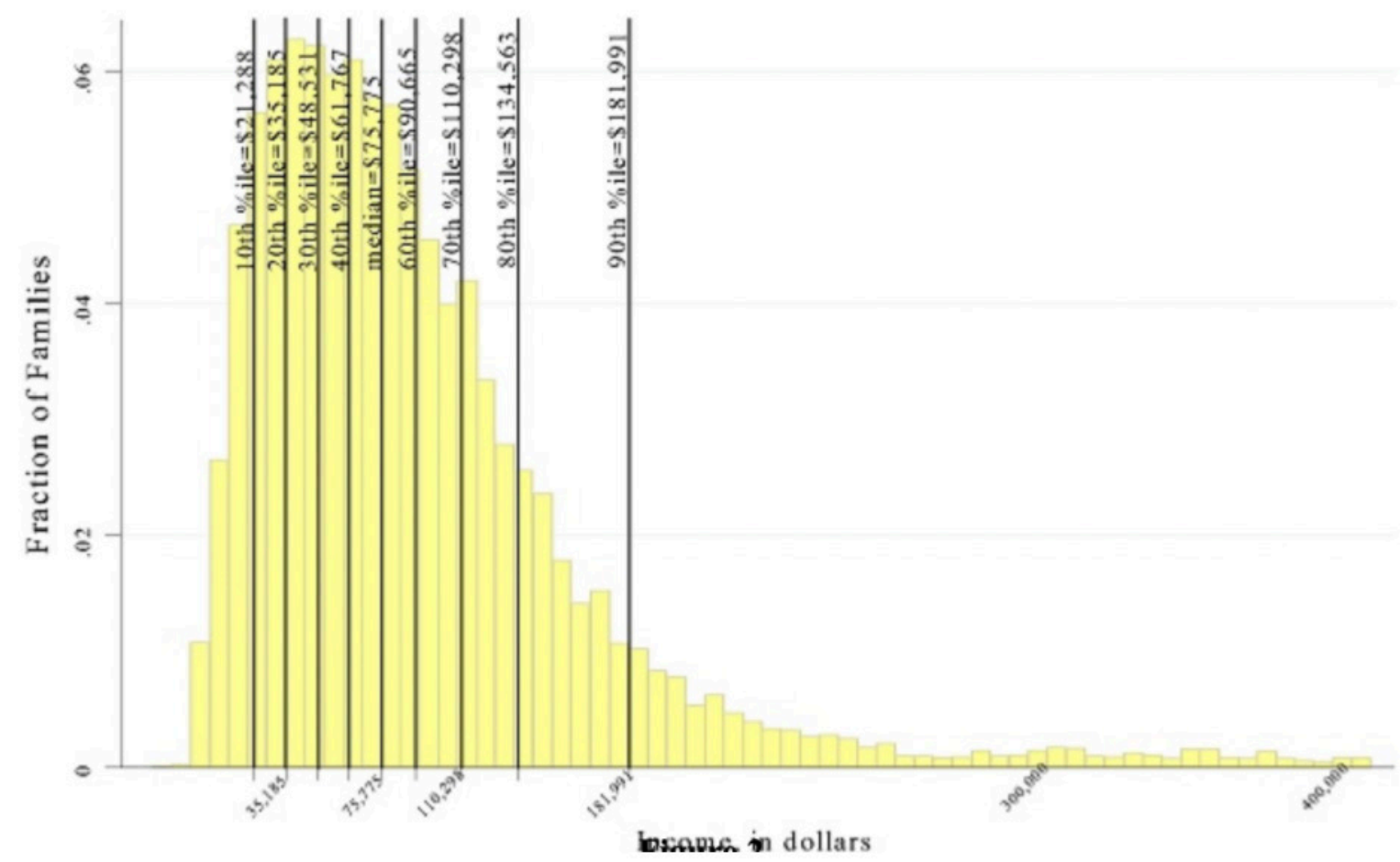

Figure 1

In this study, the definition of "low-income" will be used to differentiate low-income, high-achievement students and high-income, high-achievement students.

For the purposes of this study, the "high-achieving" population of high school students are also defined as based on the students who take one of two major college preparatory exams, the ACT or the SAT I. Although not every college applicant takes these standardized tests, most four-year college institutions required students to submit either an ACT or SAT I score in their applications until the 2020-21 admissions cycle, so this parameter was used to restrict the discussion of high-achieving students. Later on, the effect of test-optional policies on the placement and distribution of low-income, high-achieving students at top universities in the 2020-21 admissions cycle will be examined. With this in mind, it is found that "low-income students" — as previously understood as students from the bottom quartile of American families with a high school senior-aged child dependent - comprise less than $10 \%$ of the student population at selective colleges. 10 "High-achievement" students, income aside, are hereby defined as those students in the top $10 \%$ of standardized test takers in their graduating classes and who have an average grade-point average of an A- or above. These students, therefore, are adequately qualified for most selective institutions; the University of California at Los Angeles, for example, has an average composite SAT I score of 1405 on a 1600 scale. However, high-income students are overrepresented in the overall population of high-achieving students; 34 percent of highachieving students had family incomes in the top quartile, while just $17 \%$ fell in the fourth quartile, despite the difference in mean college aptitude test scores being just 1.6 percentile points higher for high-income, high-achieving students (Avery and Hoxby).

High-achieving students are also found in critical masses in metropolitan areas; they are more likely to be located in urban counties in New England, the Mid-Atlantic region, southern Florida, and California from the Bay

\footnotetext{
${ }^{10}$ Bowen, William, Martin Kurzweil, and Eugene Tobin. Equity and Excellence in American Higher Education. Charlottesville: University of Virginia Press, 2005.
} 
Area to San Diego. Schools with a high concentration of high-achievers are more likely to be exclusively located on the coasts or in a select few major metropolitan cities, such as Chicago or New York City. Part of this may be due to the concentration of highly-educated parents who work in these areas. In the Bay Area, for example, many parents of high school-aged children work in tech-heavy Silicon Valley, requiring an average higher education level than parents located in rural areas. Purely based on speculation, one would believe that more educated parents would raise more educated children. However, this connection is distinctly correlation, not causation: there is no statistical evidence that parentage and geography directly translates to a student's aptitude and classification as "high-achieving." Rather, a student's geography has a greater effect on the resources allocated to them during the college admissions process, which we will revisit later in this paper.

\section{Disparities in the College Application Process}

Low-income, high-achievement students are underrepresented at nearly all major college institutions in the United States. In this section, the systemic factors behind disparities in the college application process are categorized.

Firstly, the application habits of low-income versus high-income students are examined. For these purposes, a college's status as a "top school" is classified based on the average standardized testing score of admitted applicants, rather than its acceptance rate, to get a fuller picture of the academic rigor and achievement typical of students at these schools. Obviously, many top universities are recognized based on name value and prestige; however, the number of college institutions in the United States is well over 3,000, so a greater range of schools is considered in basing our qualifier on mean SAT and ACT score.

Most students apply to colleges with a range of selectivities, often using the terms "safety," "match," and "reach" schools. Here, a "safety" school is understood to be one that the student is most likely to be admitted into, a "match" school is one that closely aligns with a student's achievements and will be relatively attainable to get into, and a "reach" is one that is most highly selective and where the student is unlikely to be accepted. Although the cutoffs to determine a school's status as a safety, match, or reach depend on a student's individual statistics and the college's average standardized testing scores and GPA, one can safely assume that schools with very low acceptance rates are likely to be a reach, whereas those with a high acceptance rate are likely to be a safety school. By this logic, the Ivy League universities, most of which have acceptance rates under $10 \%$, fall squarely into the "reach" category for almost all applicants. Generally, high-achieving students apply to at least five or six schools, with the maximum number of colleges students apply to being 20 universities as per the Common Application's restrictions.

High-income, high-achieving students apply to schools with this idea in mind. High-income students apply mostly to match schools, followed by reach and then by safety schools. Low-income, high-achievement "incometypical" students (who comprise more than 50\% of all low-income students), however, apply mostly to safety schools. This distribution is highlighted in the graph below, which shows high income (purple), middle income (brown), and low income (blue) students' trends. 
Low, Middle, and High Income Students' Portfolios of College Applications Excluding Applications to Non-Selective Institutions (1 student $=$ weight of 1) blue $=$ low income, brown $=$ middle income, purple $=$ high income

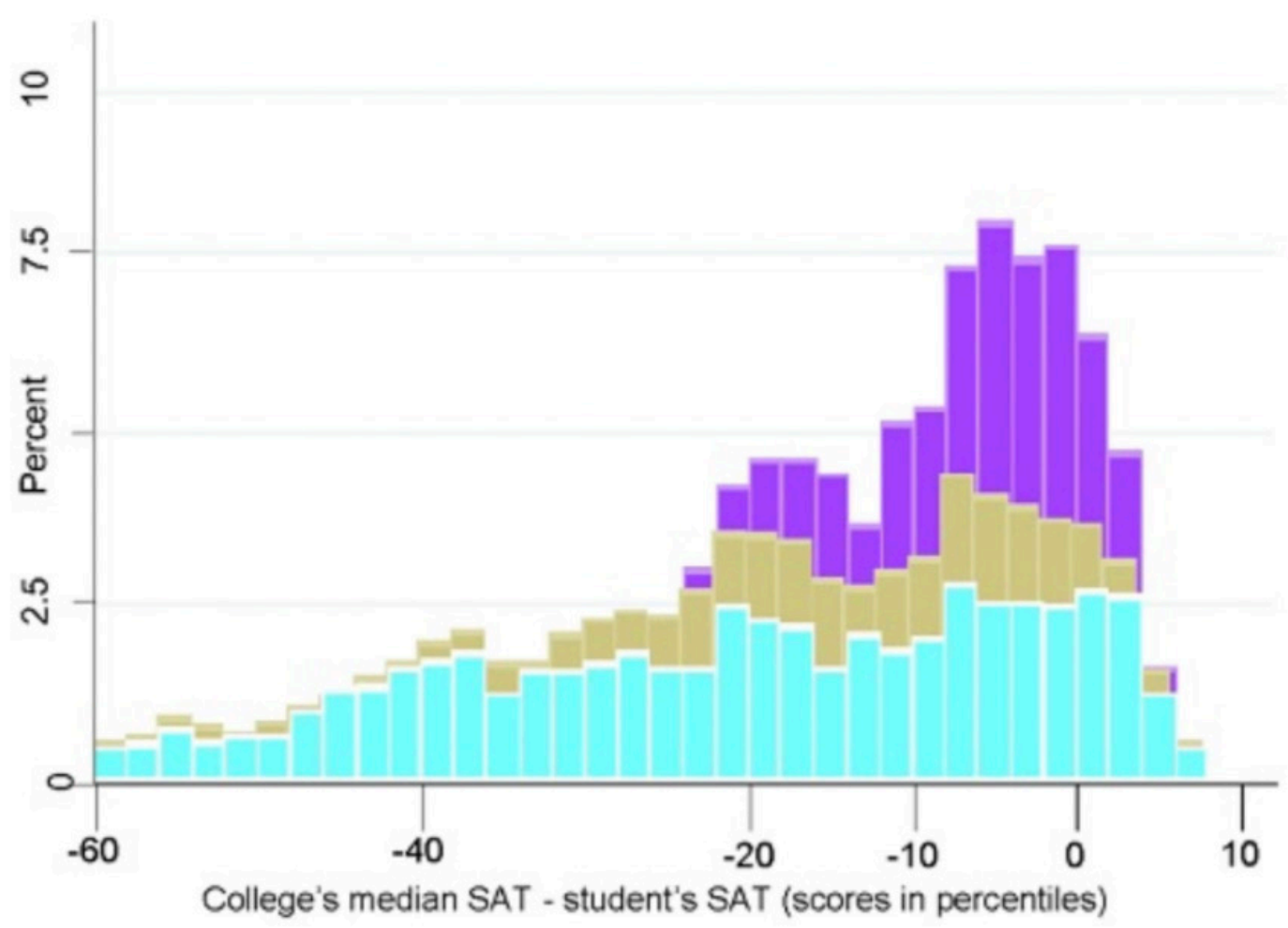

Figure 2

This next graph further shows the inconsistencies in the way low-income students apply to college, with a spike in the number of applications to safety schools that fall far below the actual student's academic potential in terms of median SAT. 


\section{Low Income Students' Portfolios of College Applications (1 student $=$ weight of 1$)$}

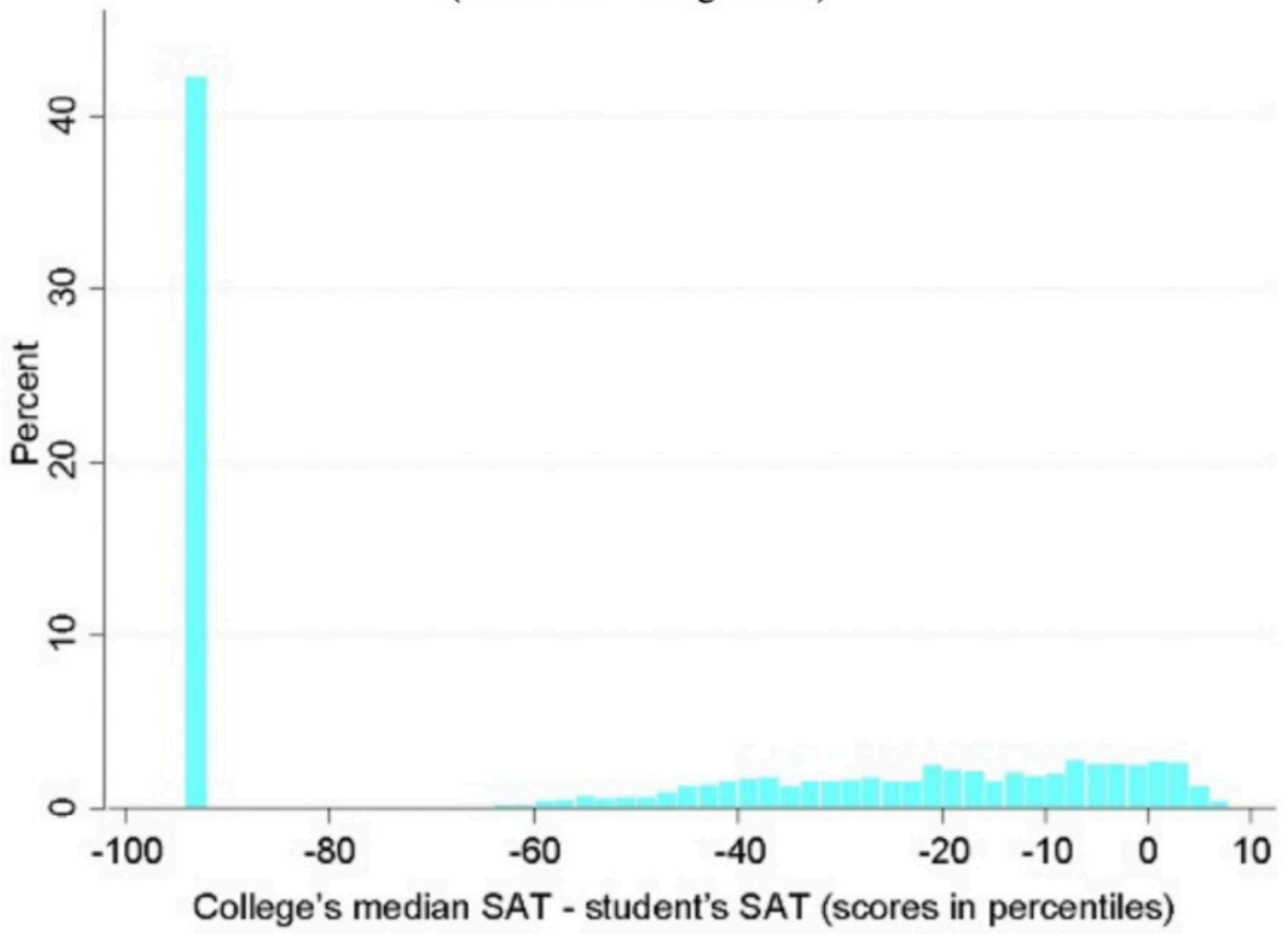

Figure 3

Here, safety schools are demonstrated to be those where the difference in SAT scores between the college and the student are negative.

As a trend, high-income students tend to strongly favor reach colleges and disfavor safety colleges and other non-selective institutions. They also favor colleges with higher sticker prices, perhaps due to the perceived prestige and/or resources associated with higher-cost universities. High-income students are also less likely to factor in things such as location, distance, and public versus private schools in their college decisions. These findings are flipped with low-income students. Low-income students are far more likely to favor non-selective universities (as shown in the two above graphs), disfavor schools with high sticker prices, and prefer schools closer to home. The only exception to this rule was with the small percentage of achievement-typical, who, for most purposes, behaved similarly to highincome students in choosing where to apply to college. As mentioned earlier, this is likely due to the critical mass of low-income, high-achieving students in magnet or feeder high schools, where they are more likely to behave similarly to their high-income, high-achievement peers due to receiving similar stimuli and resources from their school's administration.

After admission to a particular college, low-income, high-achieving and high-income, high-achieving students behave in similar ways, with identical course and internship offerings. Furthermore, no data suggests that lowincome, high-achievement students are any less qualified to attend these colleges than high-income, high-achievement students, or that they would fail to perform up to par upon their acceptance into prestigious universities. Therefore, the key difference between the two groups lies in the college applications stage of these students' lives. 


\section{Heuristics that Affect Application Decisions for Low-Income, High-Achievement Students}

In this section, the effects of behavioral economics and behavioral heuristics are examined in the decision-making process for high school seniors in the college applications process. Three factors are considered: the availability heuristic, the simulation heuristic, and status quo bias.

Before analyzing each behavioral heuristic's respective effects on a student's behavior, each one of these heuristics are defined. As a whole, heuristics are used by people every day to break down compounded problems and make complex decisions. Since humans cannot consider every piece of data in their day-to-day decisions, for obvious reasons, heuristics are a useful tool to predict the outcomes of various scenarios and simplify complex decisions, such as choosing where to go to college.

\section{The Availability Heuristic}

First, the effect of the availability heuristic in a student's decision to apply or not apply to selective colleges is taken into account. For the purposes of this study, students' knowledge of local colleges and prestigious top universities is measured based on their demonstrated interest at these schools, specifically focusing on the difference in behavior for low-income and high-income students. The primary factor used here to determine a student's demonstrated interest will be whether or not they chose to send a standardized testing to this school, as this includes most schools a student is interested in attending, whereas the colleges that the student actually ends up applying to may be affected by their Early Decision or Early Action applications (students who get into a university through an Early Decision program, for example, most often withdraw their applications at all other colleges even if they were planning on applying there earlier). In Virginia, for example, low-income students with SAT scores ranging from 1200 to 1400 were less likely to send their scores to their state flagship school, the University of Virginia, compared to high-income students with the same scores. ${ }^{11}$ Because the University of Virginia's mean student SAT score was between this range at the time of this data's collection, this discrepancy caused the underrepresentation of low-income students admitted to the university.

\footnotetext{
${ }^{11}$ Pallais, Amanda, and Sarah Turner. "Opportunities for Low-Income Students at Top Colleges and Universities: Policy Initiatives and the Distribution of Students." National Tax Journal, vol. 59, no. 2, 2006, pp. 357-386., doi:10.17310/ntj.2006.2.08.
} 


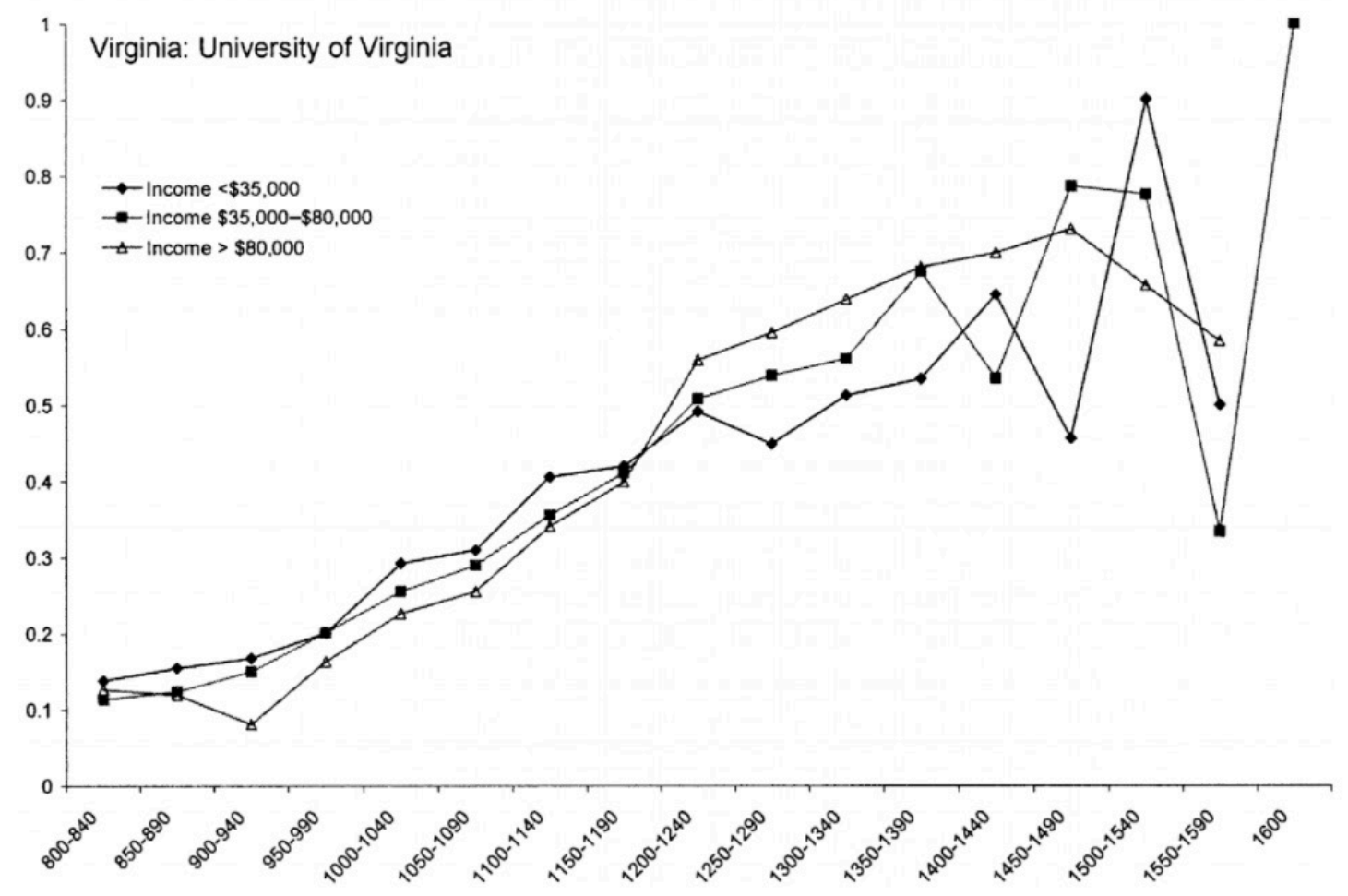

Figure 4

According to Census data, achievement-typical students are likely to have more undergraduate degree-holders in their block areas than income-typical students. From this, it can be concluded that achievement-typical students' behavior is more correlated with high-income students' behavior because of external guidance and mentorship from these alumni in their proximity compared to income-typical students, who do not have access to this resource. In addition, achievement-typical students are more likely to live in major metropolitan areas; in fact, more than $70 \%$ of achievement-typical students came from 15 cities: San Francisco, Oakland, Los Angeles, San Diego, Dallas, Houston, Chicago, Cleveland, Pittsburgh, Portland, Boston, Providence, New York, Philadelphia, and Baltimore. Therefore, achievement-typical students are likely to be more concentrated, specifically in particular feeder schools also located in these areas. Because of their proximity to other motivated students and alumni who likely applied to top universities as well, achievement-typical students in urban areas and feeder schools are more likely to be exposed to information and resources about these colleges, and therefore will be more inclined to apply to these schools than income-typical students.

Achievement-typical students also are more likely to receive information about top colleges through their schools. As most achievement-typical students live in metropolitan areas and are concentrated in large feeder high schools, their access to resources like college counselors and college admissions officers is much greater than incometypical students in suburban or rural areas. Counselor to student ratios, for example, are much lower in private and public feeder high schools compared to regular public high schools, with many competitive feeder schools also offering dedicated college counselors that follow up with individual students on their personal college plans. In addition, because income-typical students (who make up the large majority of low-income, high-achieving students) are dispersed throughout the nation, they are more likely to be the only or one of few high-achieving students in their school or area. Therefore, their school counselors and staff would likely not have as much relevant information to offer on the college admissions process, especially with respect to selective and prestigious top universities. Admissions officers are also more likely to visit achievement-typical students in metropolitan areas than income-typical students in 
suburban and rural areas. Even for colleges who prioritize diversifying their student body through seeking out lowincome, high-achieving students, there is often no "reward" for visiting suburban and rural areas in college tours when there is a critical mass of these students at magnet and feeder high schools already. In this sense, the opportunity cost and financial cost of going out of their way to visit suburban and rural high schools outweighs the ease of recruiting achievement-typical students from major metropolitan areas, meaning that income-typical students from suburban and rural areas are less likely to meet with admissions officers and find out information about specific top universities. Therefore, income-typical students' scope of influence lies largely in the information available to them - that is, immediate family and friends, alumni, and college resources at their respective high schools.

This behavior lines up with the availability heuristic — students will use this information (anecdotal evidence from friends and alumni, available resources like college counseling and college resources, and access to college recruiters and admissions officers) to decide which colleges they apply to. Information from friends and family is also more likely to be salient than information found on the Internet or through general college resources; hearing an anecdote about a cousin who went to a particular local college may have more of an impact on a student's decision to apply to that school than statistical evidence. Another example of the availability heuristic negatively impacting income-typical students' college applications decisions is with the consideration of financial aid. For income-typical students, paying for college often poses significant financial strain on their families, which can lead these students to discount expensive, prestigious universities when applying to college in favor of lower-cost state and community colleges. As found earlier in this paper, the financial aid offered by top prestigious universities can often make the cost of attendance lower than it would be for a state university. However, because of a lack of available resources and college counseling for income-typical students, these students would not be aware of this benefit, and would therefore exclude more expensive top universities from their college lists. ${ }^{12}$ For income-typical students, who often do not have access to college consulting resources, applying to nearby and safety colleges makes sense given the lack of information they have regarding prestigious universities.

This behavior is also explained by the "feature-positive" effect: people place greater emphasis on what is present than what is absent. ${ }^{13}$ A relevant example of this effect would be in a person's perception of their health; if one is healthy, they are unlikely to think about being sick. In terms of the college application question, income-typical students would be more likely to consider their present options (local colleges and state schools), rather than the options that have not been presented to them (out-of-state and prestigious top universities).

\section{The Simulation Heuristic}

Another related heuristic considered by high school students when choosing where to apply for college is the simulation heuristic; that is, if a student can see themselves attending a specific college. Some factors, such as availability or friends and family who have attended these colleges, will have an effect on a student's ability to perceive themselves as a student at a specific college. For example, hearing about a sibling who went to the local community college and their experiences would make one more able to picture themselves in that position as compared to with a prestigious top university, where the student may not have any known contact attending that school.

In addition, because of local and community colleges' proximity to students, students are likely to receive more information about these schools in the form of live info sessions, brochures, and targeted advertisements. Therefore, they maintain more salience and visibility in students' minds compared to competitive top universities, so students later find it easier to picture themselves attending.

\footnotetext{
${ }^{12}$ Choy, Susan P. "Students Whose Parents Did Not Go to College: Postsecondary Access, Persistence, and Attainment.” PsycEXTRA Dataset, 2001, doi:10.1037/e492182006-021.
}

${ }^{13}$ Dobelli, Rolf, et al. The Art of Thinking Clearly. PTS Publishing House, 2015. 


\section{Status Quo Bias}

Status quo bias is yet another behavioral economics heuristic that can affect a low-income, high-achieving student's decision to apply to a particular selective university or not. Status quo bias, in essence, is the idea that, given a choice, people tend to stick with a default rather than opting for a change. ${ }^{14}$ In the context of college applications, the environment that a student has grown up with and is used to can have the effect of becoming their standard for which they base their college applications on; if a particular school's culture, location, or atmosphere is significantly different than a student's hometown, they may not even apply. For income-typical students who come from lower-income areas, this heuristic may apply itself in how students consider the available opportunities in their area versus the opportunities available at prestigious universities. Considering the fact that many low-income neighborhoods have a lower percentage of students, on average, who go on to four-year institutions out of high school, an income-typical graduating senior may observe that many of their friends are going on to local community colleges or vocational schools, rather than opting for a four-year college further away. In conformity with the status quo bias, this student may opt to also choose a local educational opportunity rather than choosing to apply to a prestigious university because of the fact that they are surrounded by people who are doing the same and want to conform to the standard of that community. And, as demonstrated with the simulation heuristic, information from local community colleges and vocational schools is likely to be presented in a more obvious way to students, especially those in low-income communities where students often go on to attend these schools. Therefore, these income-typical students receive stimuli that contributes to the feeling of status quo bias, or the idea that they should choose a less prestigious school because of the actions of people in their home community.

\section{Interventions and Solutions}

To increase the number of income-typical students who apply to top universities, several proposed interventions in the college applications process will be considered, including the phasing in of test-optional policies and virtual recruitment during the COVID-19 pandemic, as well as income-based FAFSA assistance and alumni intervention. These interventions are intended to specifically target the barriers that affect low-income, high-achieving students.

\section{Test-Optional Policies}

In light of the ongoing COVID-19 pandemic, several universities have shifted to "test-optional" or "test-blind" policies, in which applicants can choose whether or not to submit standardized testing scores to be considered for admission. Pitzer College, a liberal arts school among the first to switch to a test-optional policy even before the onstart of the pandemic, claimed that implementing this testing policy contributed to a " $58 \%$ increase in diversity." 15 Again, in 2014, Bates College presented a study of more than 123,000 students at 33 colleges to the National Association of College Admissions Counselors, which showed that minority students — including women, first-generation applicants, Pell Grant recipients, and students with disabilities - were more likely to apply to college as test-optional if presented the chance. The study also found that between those who submitted standardized test scores and those who

14 “Status Quo Bias - Biases \& Heuristics.” The Decision Lab, 22 Jan. 2021, thedecisionlab.com/biases/status-quobias/.

15 Pros, Noodle. "When Colleges Go Test-Optional, Who Benefits?” Forbes, Forbes Magazine, 30 July 2015, www.forbes.com/sites/noodleeducation/2015/07/30/when-colleges-go-test-optional-who-bene-

fits/?sh=69e05d847807. 
didn't, there was no significant difference in cumulative grade-point averages or graduation rates. ${ }^{16}$ In other words, the quality of admitted students did not decline after the implementation of a test-optional policy.

In the 2020-21 application cycle, many colleges also shifted to test-optional policies in light of test center closures during the pandemic. A study conducted by UC Berkeley graduate student Zachary Bleemer examined a now-obsolete state policy that granted students within the top $4 \%$ of their graduating class admission to a UC campus for college between 2001 and 2011. The study found that students who were accepted as a result of this policy tended to be more diverse than in other years, with $40 \%$ of these students identifying as Black or Hispanic. ${ }^{17}$ Another study found that Texas's "top 10\%" approach to college admissions (which automatically grants students in the top 10\% of their class admission to all state-funded universities) drew in more underrepresented students who were found to graduate at higher rates. ${ }^{18}$ In fall 2021, the UC application system saw an increase in application numbers for the 202122 academic year, with the percentage of underrepresented students increasing slightly as a result of test-optional policies. ${ }^{19}$ Income-typical students are often those who could benefit the most from attending selective universities (which often provide access to resources not available at local colleges), and with the implementation of test optional policies, their enrollment and application numbers could increase.

These test-optional policies could potentially alleviate the effects of the availability heuristic for low-income, high-achieving high school students because they would allow for a greater number of students to apply to selective universities that they typically may not have applied to. This would mean that these students are now able to consider a wider variety of selective colleges in their college applications, allowing for greater diversity in college acceptances.

\section{Virtual College Tours and Recruitment}

As another result of the COVID-19 pandemic, most universities could not host traditional recruitment efforts in person, including campus tours, admissions officers' visits, and student panels. Instead, many of these schools have transitioned to virtual visits using platforms such as Zoom and Google Meet. In a normal admissions year, college admissions officers usually tour high schools across the country and meet with students to speak about the benefits of their respective colleges, an opportunity that is useful for many students to decide which universities would be a good fit for them. According to Avery and Hoxby, if a college admissions officer were to visit schools with at least 20 students, students would be served in the following distribution: $92 \%$ of high-income, high-achieving students and $66 \%$ of achievement-typical students would meet with an admissions counselor, but only $17 \%$ of income typical students would. In addition, admissions officers also tend to visit schools in metropolitan areas more often than those in suburban and rural areas, which often leaves out the critical majority of income-typical students who live in these areas. However, because of the transition this year to virtual college visits and recruitment, income-typical students and students from rural areas have been able to access more information about prestigious schools that may be otherwise inaccessible to them. If these policies are continued into future years, these students may be more likely to apply to

\footnotetext{
${ }^{16}$ Hiss, William. "Defining Promise: Twenty-Five Years of Optional Testing at Bates College: 1984-2009.” 3 June 2011 .

17 Bleemer, Zachary. Top Percent Policies and the Return to Postsecondary Selectivity. Sept. 2020, zacharybleemer.com/wp-content/uploads/2020/03/ELC_Paper.pdf.
}

${ }^{18}$ Black, Sandra E., Jeffrey T. Denning, and Jesse Rothstein. (2020). Winners and Losers? The Effect of Gaining and Losing Access to Selective Colleges on Education and Labor Market Outcomes. (EdWorkingPaper: 20-211). Retrieved from Annenberg Institute at Brown University: https://doi.org/10.26300/qfxb-4433

19 Data sampled from UC Office of the President Institutional Research and Academic Planning, https://www.ucop.edu/institutional-research-academic-planning/_files/factsheets/2021/table-2.1-california-freshman-applications-by-campus-and-race-ethnicity.pdf 
prestigious colleges that would not have been on their radar without these visits, leading to an increase in diversity at these schools.

\section{Alumni Network}

Another solution that may increase the number of low-income, high-achieving students who apply to selective colleges is the creation of an alumni network. Due to the availability heuristic and status quo bias, many low-income students may not have a network of peers or alumni contacts who have applied to or attended selective institutions. This data, which is paralleled by United States Census data, illustrates a lack of applicable role models for these low-income, high-achieving students to look up to and base their college application approaches on. To counter this issue, the creation of alumni networks on a county level is proposed to connect high-achieving high school seniors with alumni from their school or other neighboring schools who may be able to provide them assistance with choosing and applying to different colleges. Alumni, unlike specific college admissions recruiters, are more likely to live in different urban, suburban, or rural areas and/or have a personal connection to a geographic area near their hometown. In fact, according to a study conducted by Jonathan Meer and Harvey Rosen at the National Bureau of Economic Research, one particular anonymous selective college had at least one alumnus in every US county. ${ }^{20}$ Intervention from these alumni, who are likely to be personally familiar with the education system and opportunities in their particular area, could be useful to not only alert low-income, high-achieving students of the existence of these colleges, but also to encourage them to follow this route despite not having peers who may be pursuing that path.

\section{Conclusion}

Many low-income, high-achieving students do not apply to prestigious universities despite being qualified to attend them, behaving in a way characteristic of their income rather than their ability. In this paper, the behavioral heuristics behind this decision were analyzed, including the effects of availability, simulation, and status quo bias, and proposed two solutions by which colleges can encourage income-typical students to apply for admission.

It was demonstrated that part of the lack of low-income students who apply to prestigious universities is due to their concentration in feeder and magnet schools, where they behave in a way typical of their achievement because of the competitive nature of their high schools. However, income-typical students are likely to live in more dispersed pockets around the country, including in rural and suburban neighborhoods, where they are less likely to receive information about colleges that would aid in the application decisions. In this paper, it was suggested that interventions to increase the population of these students who apply to prestigious universities can be modeled from existing responses to the COVID-19 pandemic to make college information more accessible to all students, regardless of income.

\section{Acknowledgments}

I would like to thank Dr. Edoardo Gallo of the University of Cambridge for taking time to review my manuscript and providing input.

\section{References}

Black, Sandra E., Jeffrey T. Denning, and Jesse Rothstein. (2020). Winners and Losers? The Effect of Gaining and Losing Access to Selective Colleges on Education and Labor Market Outcomes. (EdWorkingPaper: 20-211).

\footnotetext{
${ }^{20}$ Meer, Jonathan, and Harvey Rosen. "Does Generosity Beget Generosity? Alumni Giving and Undergraduate Financial Aid.” 2012, doi:10.3386/w17861.
} 
Retrieved from Annenberg Institute at Brown University: https://doi.org/10.26300/qfxb-4433

Bleemer, Zachary. Top Percent Policies and the Return to Postsecondary Selectivity. Sept. 2020, zacharybleemer.com/wp-content/uploads/2020/03/ELC_Paper.pdf.

Borden, Taylor. "How Ivy League Financial Aid Packages Stack up, Even amid the Coronavirus Pandemic." Business Insider, Business Insider, 4 Sept. 2020, www.businessinsider.com/how-ivy-league-financial-aid-packagesstack-up-coronavirus-tuition-2020-7.

Bowen, William, Martin Kurzweil, and Eugene Tobin. Equity and Excellence in American Higher Education. Charlottesville: University of Virginia Press, 2005.

Bureau, US Census. “2008 Comparison Guidance.” The United States Census Bureau, 9 Sept. 2020, www.census.gov/programs-surveys/acs/guidance/comparing-acs-data/2008.html.

Choy, Susan P. “Students Whose Parents Did Not Go to College: Postsecondary Access, Persistence, and Attainment." PsycEXTRA Dataset, 2001, doi:10.1037/e492182006-021.

Dobelli, Rolf, et al. The Art of Thinking Clearly. PTS Publishing House, 2015.

Engberg, Mark E., and Gregory C. Wolniak. "Examining the Effects of High School Contexts on Postsecondary Enrollment." Research in Higher Education, vol. 51, no. 2, 2010, pp. 132-153. JSTOR, www.jstor.org/stable/40542368. Accessed 15 May 2021.

Freeberg, N. 1988. "Accuracy of Student Reported Information." College Board Report Number 88-5. http://professionals.collegeboard.com/profdownload/pdf/RR\%2088-5.PDF

Hiss, William. "Defining Promise: Twenty-Five Years of Optional Testing at Bates College: 1984-2009." 3 June 2011.

Hoxby, Caroline, and Christopher Avery. “The Missing 'One-Offs': The Hidden Supply of High-Achieving, Low Income Students.” 2012, doi:10.3386/w18586.

"Princeton Announces Plan for Fall 2020, Guidelines for Undergraduates Returning to Campus." Princeton University, The Trustees of Princeton University, 6 July 2020, www.princeton.edu/news/2020/07/06/princetonannounces-plan-fall-2020-guidelines-undergraduates-returning-campus.

Martinez, Berenice, et al. Another 4 Years of High School: The Stuyvesant and Horace Mann to UChicago Pipeline. 6 Dec. 2020, cpb-us-w2.wpmucdn.com/voices.uchicago.edu/dist/8/2937/files/2020/11/MartinezReyesSong-FinalPaper.docx.

Meer, Jonathan, and Harvey Rosen. "Does Generosity Beget Generosity? Alumni Giving and Undergraduate Financial Aid.” 2012, doi:10.3386/w17861.

Pallais, Amanda, and Sarah Turner. "Opportunities for Low-Income Students at Top Colleges and Universities: Policy Initiatives and the Distribution of Students." National Tax Journal, vol. 59, no. 2, 2006, pp. 357-386., doi:10.17310/ntj.2006.2.08. 
Pros, Noodle. "When Colleges Go Test-Optional, Who Benefits?" Forbes, Forbes Magazine, 30 July 2015, www.forbes.com/sites/noodleeducation/2015/07/30/when-colleges-go-test-optional-whobenefits/?sh=69e05d847807.

"Status Quo Bias - Biases \& Heuristics." The Decision Lab, 22 Jan. 2021, thedecisionlab.com/biases/status-quobias/. 